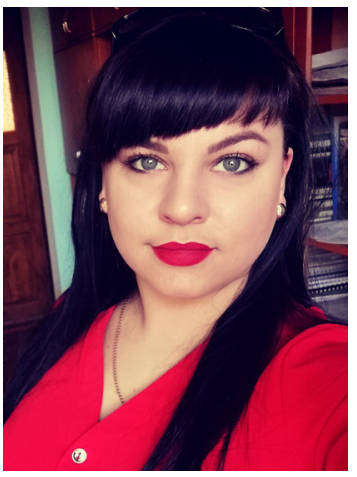

УдК: 712.41:582.477 DOI 10.31395/2310-0478-2019-2-79-83

Матусяк М. В., кандидат с.-г. наук, старший викладач, Вінницький національний аграрний університет (м. Вінниця), Україна E-mail: mikhailo1988@gmail.com

Варгатюк О. В., викладач спецдисциплін, Вінницький транспортний коледж E-mail: mega-olya1993@ukr.net

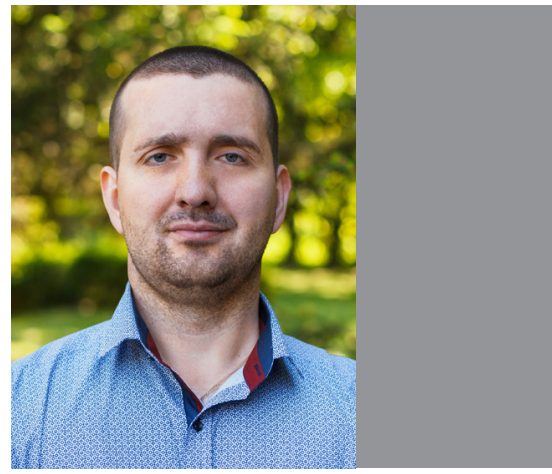

\title{
ВИКОРИСТАННЯ ПРЕДСТАВНИКІВ РОДИНИ КИПАРИСОВІ
} ПРИ ОЗЕЛЕНЕННІ ТЕРИТОРІЇ БІОСТАЦІОНАРУ ВНАУ

У статті визначено вікову та кількісну структуру насаджень родини Cupressaceae F. Neger, проведено оцінку та аналіз життєздатності та перспективності інтродукції представників даної родини.

У роботі застосовано сучасні оцінки життєздатності та перспективності інтродукції деревних рослин в умовах регіону дослідження, яку проведено згідно з методом інтегральної числової оцінки життєздатності та перспективності дерев та кущів на основі візуальних спостережень П. І. Лапіна (1973) та С. В. Сіднєвої (1973).

Згідно вікового аналізу таксономічного складу переважають молоді генеративні особини у віці від 2 до 6 років (95\%). Старих генеративних особин у віці понад 30 років найменше (5\%).

Згідно проведених досліджень із всіх видів біостаціонару ВНАУ цілком перспективними є 5 видів рослин (Сhamaесурагіs lawsoniana (Andr.) Parl.; Juniperus chinensis L.; Juniperus communis L.; Thuja occidentalis L.; Thuja orientalis L.); перспективними - 2 види (Juniperus x media L.; Juniperus scopulorum L.); менш перспективними - 2 види (Juniperus horizontalis Moench.; Thujopsis dolabrata Sieb. Et Zucc.).

Встановлено, що рівень адаптації у Chamaecyparis lawsoniana (Andr.) Parl., Chamaecyparis pisifera Sieb. et Zucc., Thujopsis dolabrata Sieb. Et Zucc., Thuja occidentalis L., Thuja plicata D. Don - високий (IV рівень адаптаціï), у Juniperus horizontalis Moench., Juniperus communis L. - добрий (III рівень адаптаціï), Juniperus chinensis L., Thuja orientalis L. середній (II рівень адаптації), Juniperus sabina L., Juniperus scopulorum L. - слабкий (I рівень адаптації).

На основі проведених досліджень розроблено пропозиції виробництву, які передбачають застосування методів та заходів щодо максимально можливого використання інтродукційного потенціалу видів родини Кипарисові, застосування оптимальних методів догляду у різних типах посадок для збереження декоративності та успішного росту інтродукованих видів.

Ключові слова: біостаціонар, інтродукція, Кипарисові, адаптація, життєздатність, акліматизація.

M. V. Matusuak

PhD of Agricultural Sciences, Senior Lecturer at Vinnytsia National Agrarian University (Vinnytsia), Ukraine

O. V. Vargatiuk

Lecturer at the Vinnitsa Transport College, (Vinnytsia), Ukraine

\section{THE USE OF CYPRIS FAMILY REPRESENTATIVES IN THE GREENING OF THE BIOSTATIONARY VSAU}

The age and quantitative structure of the plantations of the Cupressaceae F. Neger family was determined, and an assessment and analysis of the viability and prospects of the introduction of representatives of this family were conducted.

The paper uses modern estimates of the viability and prospects of introducing woody plants in the region of the study, which is carried out in accordance with the method of integrated numerical assessment of the viability and prospects of trees and shrubs based on the visual observations of P. I. Lapin (1973) and S.V. Sidneva (1973).

According to age-related analysis of taxonomic composition, young generative individuals aged 2 to 6 years predominate (95\%). The oldest generative individuals over the age of 30 are the least (5\%).

According to the conducted researches from all kinds of biostationary of VNAU 5 species of plants (Chamaecyparis lawsoniana (Andr.) Parl.; Juniperus chinensis L.; Juniperus communis L.; Thuja occidentalis L.; Thuja orientalis L.); promising 2 species (Juniperus $x$ media L.; Juniperus sopulorum L.;); less promising - 2 species (Juniperus horizontalis Moench.; Thujopsis dolabrata Sieb. Et Zucc.).

Adaptation level in Chamaecyparis lawsoniana (Andr.) Parl., Chamaecyparis pisifera Sieb. et Zucc., Thujopsis dolabrata Sieb. Et Zucc., Thuja occidentalis L., Thuja plicata D. Don - high (IV adaptation level), in Juniperus horizontalis Moench.;, Juniperus communis L. - good (III adaptation level), Thuja orientalis (II adaptation level), Juniperus sabina L., Juniperus scopulorum L. - weak (adaptation level I).

On the basis of the conducted researches, proposals for production were developed, which envisage the application of methods and measures for the maximum possible utilization of the introductory potential of species of the Cypress family, the use of optimum methods of care in different types of plantings for preserving the decorative and successful growth of the introduced species.

Key words: biostationary, introduction, cypress, adaptation, viability, acclimatization.

Постановка проблеми. Проблема оптимізації асортименту і якості деревних і чагарникових рослин, що використовуються в зеленому будівництві, в даний час $€$ актуальною. Значну роль у формуванні культурних фітоландшафтів традиційно відводять рослинамінтродуцентам, використання яких підвищує декоративну цінність посадок [2].

Серед інтродуцентів особливе місце займають вічнозелені хвойні рослини і, передусім, представники родини Кипарисових (Cupressaceae F. Neger), які відрізняються стійкістюпротихворобішкідників, зберігають декоративні якості протягом усього року, мають фітонцидні 
властивості [1].

Аналіз останні досліджень та публікацій. Широке і успішне використання представників родини Cupressaceae F. Neger у культурі можливе на основі всебічного вивчення біологічних, екологічних і народногосподарських особливостей цих рослин. Проблемою інтродукції та акліматизації Кипарисових в культурі займалися такі науковці як Кохно М. О. (2001), Лапін П. І. (1973), Цицюра Н. I. (2007) та ін. [4,5].

Метою статті було виявити таксономічний склад, дослідити біоекологічні особливості і оцінити перспективи інтродукції і практичного використання представників родини Cupressaceae F. Neger на території біостаціонару BHAY.

Методика дослідження. Дослідження проводили стаціонарно та маршрутним методом протягом 20172019 р.р. При цьому вивчали результати культивування хвойних на території біостаціонару ВНАУ.
Таксономічний склад вивчали шляхом маршрутного обстеження насаджень. Класифікацію життєвих форм здійснювали згідно з системою К. Раункієра. Опис досліджуваних видів та форм проводили, використовуючи напрацювання О. І. Колесников (1974), Г. Крюссмана (1986), М. А. Кохна (2001), О.А.Калініченка (2003) [46] та на основі власних спостережень.

Для оцінки життєздатності та перспективності інтродукції деревних рослин в умовах регіону дослідження, було визначено перспективність дерев та кущів на основі візуальних спостережень П. І. Лапіна (1973) та С. В. Сіднєвої (1973).

Основні результати дослідження. Озеленення, виходячи із екологічних, соціально-економічних і естетичних потреб не могло розвиватися без залучення в цей процес нових інтродукованих видів рослин.

Як відомо, інтродукція рослин пов'язана з мінливістю та пристосуванням до нових кліматичних умов. Залежні

\begin{tabular}{|c|c|c|c|c|}
\hline \multicolumn{5}{|c|}{ Таксономічний склад родини Cupressaceae біостаціонару ВНАУ } \\
\hline Родина & Рід & Вид & Форма & Дата \\
\hline $\begin{array}{c}\text { Кипарисові } \\
\text { (Cupressaceae) }\end{array}$ & $\begin{array}{c}\text { Кипарисовик } \\
\text { (Chamaecyparis) }\end{array}$ & $\begin{array}{c}\text { Chamaecyparis lawsoniana } \\
\text { (Andr.) Parl.- Кипарисовик } \\
\text { Лавсона }\end{array}$ & $\begin{array}{c}\text { Chamaecyparis lawsoniana Beissn. } \\
\text { «Alumii» - Кипарисовик Лавсона } \\
\text { «Алюмі» }\end{array}$ & 10.03 .15 \\
\hline $\begin{array}{c}\text { Кипарисові } \\
\text { (Cupressaceae) }\end{array}$ & $\begin{array}{c}\text { Кипарисовик } \\
\text { (Chamaecyparis) }\end{array}$ & $\begin{array}{c}\text { Chamaecyparis pisifera Sieb. } \\
\text { et Zucc. - Кипарисовик } \\
\text { горіхоплідний }\end{array}$ & $\begin{array}{c}\text { Chamaecyparis pisifera Sieb. et } \\
\text { Zucc. «Aurea» - Кипарисовик } \\
\text { горіхоплідний «Ауреа» }\end{array}$ & 12.03 .15 \\
\hline $\begin{array}{c}\text { Кипарисові } \\
\text { (Cupressaceae) }\end{array}$ & $\begin{array}{c}\text { Ялівець } \\
\text { (Juniperus) }\end{array}$ & $\begin{array}{c}\text { Juniperus chinensis L.- Ялівець } \\
\text { китайський }\end{array}$ & $\begin{array}{l}\text { Juniperus chinensis L. «Old Gold»- } \\
\text { Ялівець китайський «Олд Голд» }\end{array}$ & 05.04 .15 \\
\hline $\begin{array}{c}\text { Кипарисові } \\
\text { (Cupressaceae) }\end{array}$ & $\begin{array}{c}\text { Ялівець } \\
\text { (Juniperus) }\end{array}$ & $\begin{array}{c}\text { Juniperus chinensis L.- Ялівець } \\
\text { китайський }\end{array}$ & $\begin{array}{c}\text { Juniperus chinensis L. «Pfitzeriana» } \\
\text { - Ялівець китайський } \\
\text { «Пфітцеріана» }\end{array}$ & 12.03 .15 \\
\hline $\begin{array}{c}\text { Кипарисові } \\
\text { (Cupressaceae) }\end{array}$ & $\begin{array}{c}\text { Ялівець } \\
\text { (Juniperus) }\end{array}$ & $\begin{array}{l}\text { Ялівець горизонтальний } \\
\text { Juniperus horizontalis }\end{array}$ & $\begin{array}{c}\text { Juniperus horizontalis Moench. «Blue } \\
\text { Chip» - Ялівець горизонтальний } \\
\text { «Блу Чіп» }\end{array}$ & 24.10 .15 \\
\hline $\begin{array}{c}\text { Кипарисові } \\
\text { (Cupressaceae) }\end{array}$ & $\begin{array}{c}\text { Ялівець } \\
\text { (Juniperus) }\end{array}$ & $\begin{array}{l}\text { Ялівець горизонтальний } \\
\text { Juniperus horizontalis } L \text {. }\end{array}$ & $\begin{array}{c}\text { Juniperus horizontalis Moench. } \\
\text { «Glauca» - Ялівець горизонтальний } \\
\text { «ґлаука» }\end{array}$ & 24.10 .15 \\
\hline $\begin{array}{c}\text { Кипарисові } \\
\text { (Cupressaceae) }\end{array}$ & $\begin{array}{l}\text { Ялівець } \\
\text { (Juniperus) }\end{array}$ & $\begin{array}{c}\text { Juniperus sabina L. - Ялівець } \\
\text { козацький }\end{array}$ & $\begin{array}{c}\text { Juniperus sabina L. «Albo-variegata» } \\
\text { - Ялівець козацький «Альбо- } \\
\text { варієґата» }\end{array}$ & 30.10 .15 \\
\hline $\begin{array}{c}\text { Кипарисові } \\
\text { (Cupressaceae) }\end{array}$ & $\begin{array}{c}\text { Ялівець } \\
\text { (Juniperus) }\end{array}$ & $\begin{array}{c}\text { Juniperus sabina } L . \text { - Ялівець } \\
\text { козацький }\end{array}$ & $\begin{array}{c}\text { Juniperus sabina L. «Variegata» - } \\
\text { Ялівець козацький «Варієґата» }\end{array}$ & 23.10 .15 \\
\hline $\begin{array}{c}\text { Кипарисові } \\
\text { (Cupressaceae) }\end{array}$ & $\begin{array}{c}\text { Ялівець } \\
\text { (Juniperus) }\end{array}$ & $\begin{array}{l}\text { Juniperus scopulorum L. - } \\
\text { Ялівець скельний }\end{array}$ & $\begin{array}{c}\text { Juniperus scopulorum L. «Sky } \\
\text { rocket»- Ялівець скельний } \\
\text { «Скай роккет» }\end{array}$ & 20.10. 16 \\
\hline $\begin{array}{c}\text { Кипарисові } \\
\text { (Cupressaceae) }\end{array}$ & $\begin{array}{c}\text { Ялівець } \\
\text { (Juniperus) } \\
\end{array}$ & $\begin{array}{l}\text { Juniperus communis L. - } \\
\text { Ялівець звичайний }\end{array}$ & & 20.10 .16 \\
\hline $\begin{array}{c}\text { Кипарисові } \\
\text { (Cupressaceae) }\end{array}$ & $\begin{array}{c}\text { Туя } \\
\text { (Thuja) }\end{array}$ & $\begin{array}{c}\text { Thuja occidentalis L. Туя } \\
\text { західна }\end{array}$ & \begin{tabular}{|c|} 
Thuja occidentalis L. «Aurea-plicata» \\
- Туя західна «Ауреа-пліката»
\end{tabular} & 25.03 .16 \\
\hline $\begin{array}{c}\text { Кипарисові } \\
\text { (Cupressaceae) }\end{array}$ & $\begin{array}{c}\text { Туя } \\
\text { (Thuja) }\end{array}$ & $\begin{array}{c}\text { Thuja occidentalis L. Туя } \\
\text { західна }\end{array}$ & $\begin{array}{c}\text { Thuja occidentalis L. «Compacta» - } \\
\text { Туя західна «Компакта» }\end{array}$ & 25.03 .16 \\
\hline $\begin{array}{c}\text { Кипарисові } \\
\text { (Cupressaceae) }\end{array}$ & $\begin{array}{l}\text { Туя } \\
\text { (Thuja) }\end{array}$ & $\begin{array}{c}\text { Thuja occidentalis L. Туя } \\
\text { західна }\end{array}$ & $\begin{array}{c}\text { Thuja occidentalis L. «Globosa» - } \\
\text { Туя західна «Глобоса» }\end{array}$ & 16.03 .16 \\
\hline $\begin{array}{c}\text { Кипарисові } \\
\text { (Cupressaceae) }\end{array}$ & $\begin{array}{c}\text { Туя } \\
\text { (Thuja) }\end{array}$ & $\begin{array}{c}\text { Thuja occidentalis L. Туя } \\
\text { західна }\end{array}$ & $\begin{array}{c}\text { Thuja occidentalis L. «Smaragd» - } \\
\text { Туя західна «Смарагд» }\end{array}$ & 21.10 .16 \\
\hline $\begin{array}{c}\text { Кипарисові } \\
\text { (Cupressaceae) }\end{array}$ & $\begin{array}{c}\text { Туя } \\
\text { (Thuja) }\end{array}$ & $\begin{array}{c}\text { Thuja occidentalis L. Туя } \\
\text { західна }\end{array}$ & $\begin{array}{c}\text { Туя західна (Thuja occidentalis } \\
\text { L. «Аигеа plicata») - Туя західна } \\
\text { «Золотисто- кінчикова» }\end{array}$ & 21.10 .16 \\
\hline $\begin{array}{c}\text { Кипарисові } \\
\text { (Cupressaceae) }\end{array}$ & $\begin{array}{c}\text { Туя } \\
\text { (Thuja) }\end{array}$ & $\begin{array}{c}\text { Thuja occidentalis L. Туя } \\
\text { західна }\end{array}$ & $\begin{array}{c}\text { Tуя західна (Thuja осcidentalis } \\
\text { L. «Teddi bear») - Туя західна } \\
\text { «Тедді» }\end{array}$ & 21.10 .16 \\
\hline $\begin{array}{c}\text { Кипарисові } \\
\text { (Cupressaceae) }\end{array}$ & $\begin{array}{c}\text { Туя } \\
\text { (Thuja) }\end{array}$ & Thuja orientalis L. - Туя східна & $\begin{array}{c}\text { Thuja orientalis L. «Fastigata» - } \\
\text { Туя східна «Фастіґіата» }\end{array}$ & 29.04 .04 \\
\hline $\begin{array}{c}\text { Кипарисові } \\
\text { (Cupressaceae) }\end{array}$ & $\begin{array}{c}\text { Туя } \\
\text { (Thuja) }\end{array}$ & $\begin{array}{c}\text { Thuja plicata D.Don.- Туя } \\
\text { складчаста }\end{array}$ & $\begin{array}{c}\text { Thuja plicata D.Don. «Albo- } \\
\text { variegata»- Туя складчаста } \\
\text { «Альбо-варієґата» } \\
\end{array}$ & 25.03 .17 \\
\hline $\begin{array}{c}\text { Кипарисові } \\
\text { (Cupressaceae) }\end{array}$ & $\begin{array}{l}\text { Туйовик } \\
\text { (Thujopsis) }\end{array}$ & $\begin{array}{c}\text { Thujopsis dolabrata } \\
\text { Sieb. Et Zucc.- Туйовик } \\
\text { долотоподібний }\end{array}$ & $\begin{array}{l}\text { Thujopsis dolabrata Sieb. et } \\
\text { Zuсc. «Variegata»- Туйовик } \\
\text { долотоподібний «Варієґата» }\end{array}$ & 21.03 .17 \\
\hline
\end{tabular}




\section{Вікова та кількісна структура насаджень біостаціонару ВНАУ}

\begin{tabular}{|c|c|c|c|}
\hline № & Назва рослини & Кількість рослин, (шт.) & Вік рослини, років \\
\hline 1. & Chamaecyparis lawsoniana (Andr.) Parl. & 3 & 4 \\
\hline 2. & Chamaecyparis lawsoniana Beissn. «Alumii» & 1 & 2 \\
\hline 3. & Chamaecyparis pisifera Sieb. et Zucc. & 2 & 3 \\
\hline 4. & Chamaecyparis pisifera Sieb. et Zucc. «Aurea» & 1 & 3 \\
\hline 5. & Juniperus chinensis L. & 5 & 4 \\
\hline 6. & Juniperus chinensis L. «Old Gold» & 2 & 3 \\
\hline 7. & Juniperus chinensis L. «Pfitzeriana» & 2 & 3 \\
\hline 8. & Juniperus horizontalis L. & 4 & 5 \\
\hline 9. & Juniperus horizontalis Moench. «Blue Chip» & 3 & 6 \\
\hline 10. & Juniperus horizontalis Moench. «Glauca» & 2 & 5 \\
\hline 11. & Juniperus sabina L. & 3 & 4 \\
\hline 12. & Juniperus sabina L. «Variegata» & 2 & 3 \\
\hline 13. & Juniperus scopulorum L. «Sky rocket» & 3 & $\begin{array}{l}3 \\
5\end{array}$ \\
\hline 14. & Juniperus communis L. & 4 & 6 \\
\hline 15. & Thuja occidentalis L. & 2 & 4 \\
\hline 16. & Thuja occidentalis L. «Compacta» & 3 & 3 \\
\hline 17. & Thuja occidentalis L. «Globosa» & 2 & 3 \\
\hline 18. & Thuja occidentalis L. «Smaragd» & 3 & 6 \\
\hline 19. & Thuja occidentalis L. «Aurea plicata» & 1 & 2 \\
\hline 20. & Thuja orientalis L. & 5 & 5 \\
\hline 21. & Thuja orientalis L. «Fastigata» & 1 & 4 \\
\hline 22. & Thuja plicata D.Don. & 2 & 4 \\
\hline 23. & Thujopsis dolabrata Sieb. Et Zucc. & 1 & 3 \\
\hline 24. & Thujopsis dolabrata Sieb. et Zucc. «Variegata» & 1 & 3 \\
\hline
\end{tabular}

Аналіз життєздатності та перспективності інтродукції видів родини Cupressaceae $F$. Neger на території біостаціонару ВНАУ

Рід, вид

\begin{tabular}{|c|c|c|c|c|c|c|c|c|}
\hline 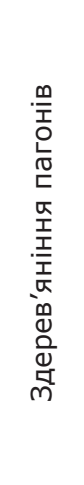 & 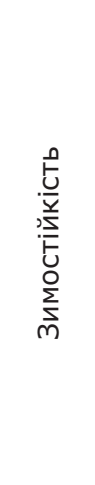 & 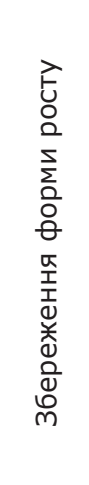 & 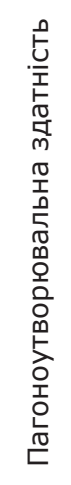 & 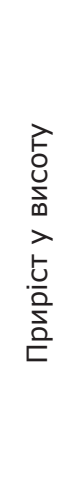 & 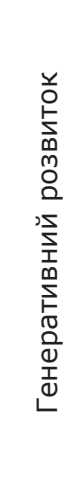 & 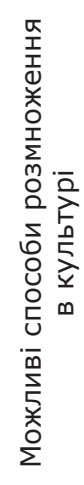 & 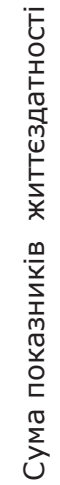 & 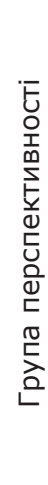 \\
\hline $1-20$ & $5-25$ & $5-10$ & $1-5$ & $2-5$ & $1-25$ & $5-10$ & - & - \\
\hline 20 & 25 & 10 & 5 & 5 & 25 & 7 & 97 & I \\
\hline 20 & 25 & 10 & 5 & 5 & 25 & 7 & 97 & I \\
\hline 20 & 25 & 10 & 5 & 5 & 20 & 5 & 90 & I \\
\hline 15 & 20 & 10 & 5 & 5 & 15 & 6 & 76 & III \\
\hline 20 & 25 & 10 & 5 & 5 & 21 & 5 & 91 & I \\
\hline 20 & 25 & 10 & 5 & 5 & 15 & 5 & 85 & II \\
\hline 20 & 25 & 10 & 5 & 5 & 25 & 5 & 95 & $\mathrm{I}$ \\
\hline 20 & 25 & 10 & 5 & 5 & 20 & 5 & 90 & I \\
\hline 20 & 20 & 10 & 5 & 5 & 10 & 5 & 75 & III \\
\hline 20 & 15 & 5 & 5 & 5 & 15 & 10 & 75 & III \\
\hline 20 & 25 & 10 & 5 & 6 & 15 & 5 & 86 & II \\
\hline
\end{tabular}

від еколого-історичного походження рослини неоднаково пристосовуються до нових умов вирощування, які змінюють не лише функції, а іноді і форму (дерева перетворюються в кущі, кущі - в багаторічники) [7].

Перспектива інтродукції значною мірою залежить від вивчення ритму росту та розвитку рослин, причиннонаслідкових зв'язків між рослиною та умовами існування. Вивчення реакції рослин на кліматичні умови нового району зростання допомагає усунути слабкі ланки в загальному ланцюгу адаптації рослинного організму та 


\begin{tabular}{|c|c|c|c|c|c|c|}
\hline $\begin{array}{l}\text { ㅁ } \\
\frac{1}{0} \\
\frac{5}{2}\end{array}$ & 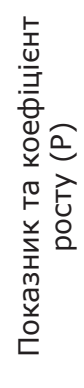 & 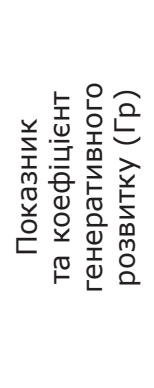 & 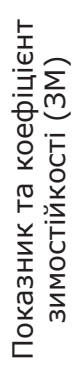 & 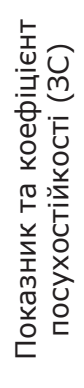 & 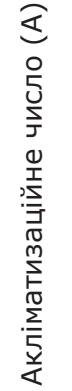 & 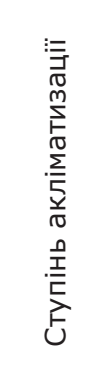 \\
\hline $\begin{array}{c}\text { Chamaecyparis lawsoniana } \\
\text { (Andr.) Parl. }\end{array}$ & 8 & 20 & 40 & 15 & 83 & Повна \\
\hline $\begin{array}{c}\text { Chamaecyparis pisifera Sieb. } \\
\text { et Zucc. }\end{array}$ & 10 & 20 & 50 & 15 & 95 & Повна \\
\hline Juniperus chinensis L. & 8 & 5 & 40 & 15 & 68 & Добра \\
\hline Juniperus communis L. & 10 & 25 & 50 & 15 & 100 & Повна \\
\hline Juniperus horizontalis L. & 10 & 5 & 50 & 15 & 80 & Добра \\
\hline Juniperus scopulorum L. & 10 & 5 & 40 & 15 & 90 & Повна \\
\hline Juniperus Sabina L. & 10 & 10 & 50 & 15 & 85 & Повна \\
\hline Thuja orientalis L. & 8 & 5 & 40 & 15 & 68 & Добра \\
\hline Thuja occidentalis L. & 10 & 25 & 50 & 15 & 100 & Повна \\
\hline Thuja plicata D.Don & 10 & 25 & 50 & 15 & 100 & Повна \\
\hline $\begin{array}{c}\text { Thujopsis dolabrata Sieb. } \\
\text { Et Zucc. }\end{array}$ & 6 & 5 & 40 & 15 & 66 & Добра \\
\hline
\end{tabular}

\begin{tabular}{|c|c|c|c|c|}
\hline \multicolumn{5}{|c|}{ Середньорічні показники рівня адаптації видів родини Cupressaceae F. Neger } \\
\hline Вид & $\begin{array}{l}\text { Зимостійкість, } \\
\text { бал }\end{array}$ & $\begin{array}{c}\text { Посухостійкість } \\
\text { бал }\end{array}$ & $\begin{array}{l}\text { Репродуктивна } \\
\text { здатність, бал }\end{array}$ & $\begin{array}{c}\text { Адаптивний } \\
\text { показник }\end{array}$ \\
\hline $\begin{array}{c}\text { Chamaecyparis lawsoniana } \\
\text { (Andr.) Parl. }\end{array}$ & 5 & 5 & 5 & 125 \\
\hline Chamaecyparis pisifera Sieb. et Zucc. & 5 & 5 & 5 & 125 \\
\hline Juniperus chinensis L. & 5 & 5 & 3 & 75 \\
\hline Juniperus horizontalis Moench. & 5 & 5 & 4 & 100 \\
\hline Juniperus sabina L. & 5 & 5 & 1 & 25 \\
\hline Juniperus scopulorum L. & 5 & 5 & 2 & 50 \\
\hline Juniperus communis L. & 5 & 5 & 4 & 100 \\
\hline Thuja occidentalis L. & 5 & 5 & 1 & 100 \\
\hline Thuja orientalis L. & 5 & 5 & 3 & 75 \\
\hline Thuja plicata D. Don & 5 & 5 & 5 & 125 \\
\hline Thujopsis dolabrata Sieb. Et Zucc. & 5 & 5 & 5 & 125 \\
\hline
\end{tabular}

виявити перспективу інтродукції нових видів [6].

Аналіз таксономічного складу родини Cupressaceae F. Neger, які культивуються в умовах відкритого ґрунту біостаціонару Вінницького національного аграрного університету показав, що родина включає 11 видів та 18 форм (табл. 1).

Згідно вікового аналізу таксономічного складу переважають молоді генеративні особини у віці від 2 до 6 років (95\%). Старих генеративних особин у віці понад 30 років найменше (5\%) (табл. 2). Більшість видів, які росли на території біостаціонару на початку його створення, ростуть в ньому і сьогодні. Також збереглися старі насадження (понад 30 років), за якими певний період не здійснювали належного догляду, тому вижили найстійкіші. Завдяки створенню спеціальної програми та збільшенню фінансування за короткий період колекція родини Cupressaceae F. Neger значно збільшилась. Сучасний колекційний фонд родини Cupressaceae $\mathrm{F}$. Neger налічує 4 роди, 11 видів та 18 форм.

Дослідження проводились впродовж 2017-2019 р. р. на території біостаціонару Вінницького національного аграрного університету за відомими методиками аналізу життєздатності та перспективності інтродукції видів родини Cupressaceae F. Neger. Характеризувались і оцінювались 11 видів родини. Результати досліджень наведено у таблиці 3.

Отже, згідно методики П. І. Лапіна (1973), С. В. Сіднєвої (1973) із всіх видів біостаціонару ВНАУ цілком перспективними $є 6$ видів рослин (Chamaecyparis lawsoniana (Andr.) Parl.; Juniperus chinensis L.; Juniperus communis L.; Thuja occidentalis L.; Thuja orientalis L., Juniperus sabina L.); перспективними - 2 види (Juniperus $x$ media L.; Juniperus scopulorum L.); менш перспективними - 3 види (Juniperus horizontalis Moench.; Thujopsis dolabrata Sieb. Et Zucc., Thuja plicata D. Don) (табл. 3).

Оцінка успішності акліматизації видів родини Cupressaceae здійснювалася в умовах біостаціонару ВНАУ за методикою М. А. Кохна та О. М. Курдюка (1994), під час якої ми встановлювали коефіцієнт росту, генеративного розвитку, зимостійкості, посухостійкості. Враховуючи ці показники встановлено ступінь акліматизації представників родини Кипарисові (табл. 4). 
Виходячи 3 результатів дослідження можна сказати, що всі види акліматизувалися в природних умовах біостаціонару, зокрема, 7 видів (Chamaecyparis lawsoniana, Chamaecyparis pisifera, Juniperus Sabina, Juniperus communis, Juniperus scopulorum, Thuja occidentalis, Thuja plicata) повнісню акліматизовані, а у 4 видів (Juniperus chinensis, Juniperus horizontalis, Thuja orientalis, Thujopsis dolabrata) ступінь акліматизації добрий.

Адаптивний показник, що вказує на рівень адаптації деревних рослин відображений у табл. 5.

Таким чином, рівень адаптації у Chamaecyparis lawsoniana (Andr.) Parl., Chamaecyparis pisifera Sieb. et Zucc., Thujopsis dolabrata Sieb. Et Zucc., Thuja occidentalis L., Thuja plicata D. Don - високий (IV рівень адаптації), у Juniperus horizontalis Moench., Juniperus communis L. добрий (III рівень адаптації), Juniperus chinensis L., Thuja orientalis L. - середній (II рівень адаптації), Juniperus sabina L., Juniperus scopulorum L. - слабкий (I рівень адаптації).

Висновки. Проаналізувавши таксономічний склад родини Cupressaceae F. Neger, доведено, що він включає 4 роди, 11 видів, 18 форм.

Згідно вікового аналізу таксономічного складу переважають молоді генеративні особини у віці від 2 до 6 років $(95 \%)$. Старих генеративних особин у віці понад 30 років найменше (5\%)

Оцінка життєздатності та перспективності інтродукції свідчить про те, що із всіх видів родини Cupressaceae $F$. Neger, цілком перспективними $\epsilon 5$ видів рослин (Chamaecyparis lawsoniana (Andr.) Parl.; Juniperus chinensis L.; Juniperus communis L.; Thuja occidentalis L.; Thuja orientalis L.); перспективними - 2 види (Juniperus $x$ media L.; Juniperus scopulorum L.); менш перспективними - 2 види (Juniperus horizontalis Moench.; Thujopsis dolabrata Sieb. Et Zucc.).

Усі досліджувані види акліматизувалися в природних умовах біостаціонару, зокрема, 7 видів (Chamaecyparis lawsoniana (Andr.) Parl., Chamaecyparis pisifera Sieb. et Zucc., Juniperus Sabina L., Juniperus communis L., Juniperus scopulorum L., Thuja occidentalis L., Thuja plicata D. Don) повнісню акліматизовані, а у 4 видів (Juniperus chinensis L., Juniperus horizontalis Moench., Thuja orientalis L., Thujopsis dolabrata Sieb. Et Zucc.) ступінь акліматизації добрий. Майже всі рослини успішно пройшли акліматизацію та нині вегетують зі вступом у фазу плодоношення.

\section{Література}

1. Балабушка В. К., Маринич І. С. Хвойні дерева та кущі. Київ: Дім, сад, город, 2005. 162 с

2. Заячук В. Я. Дендрологія голонасінні : навчальний посібник. Львів: Апріорі, 2008. $656 \mathrm{C}$

3. Калініченко О. А. Декоративна дендрологія: навчальний посібник. Київ: Вища школа, 2003. 199 с.

4. Кохно М. А. Каталог дендрофлори України. Київ: Фітосоціоцентр, 2001. $235 \mathrm{c}$

5. Лапин П. И., Сиднева С. В. Оценка перспективности интродукции древесных растений по данным визуальных наблюдений. Опыт интродукции древесных растений. Москва: Наука, 1973. С. 7-68

6. Интродукции древесных растений. Москва: Наука, 1973. С. 7-68 Київ: Фітосоціоцентр, 2001. 127 с.

7. Сікура Й. Й., Капустян В.В. Інтродукція рослин (ії значення для розвитку цивілізацій, ботанічної науки та збереження різноманіття рослинного світу). Київ: 2003. 90 с.

\section{References}

1. Balabushka V. K., Marynych I. S. Khvoini dereva ta kushchi. Kiev: Dim, sad, horod, 2005. $162 \mathrm{~s}$.

2. Zaiachuk V. Ya. Dendrolohiia holonasinni : navchalnyi posibnyk. Lviv: Apriori, 2008. $656 \mathrm{~s}$.

3. Kalinichenko O. A. Dekoratyvna dendrolohiia: navchalnyi posibnyk. Kiev: Vyshcha shkola, 2003. 199 s.

4. Kokhno M. A. Kataloh dendroflory Ukrainy. Kiev: Fitosotsiotsentr, 2001. 235 s.

5. Lapin P. I., Sidneva S. V. Ocenka perspektivnosti introdukcii drevesnyh rastenij po dannym vizualnyh nabljudenij. Opyt introdukcii drevesnyh rastenij. Moscow: Nauka, 1973. S. 7-68

6. Laptev O. O. Introduktsiia ta aklimatyzatsiia roslyn z osnovamy ozelenennia. Kiev: Fitosotsiotsentr, 2001. 127 s.

7. Sikura Y. Y., Kapustian V.V. Introduktsiia roslyn (ii znachennia dlia rozvytku tsyvilizatsii, botanichnoi nauky ta zberezhennia riznomanittia roslynnoho svitu). Kiev: 2003. 90 s. 